\title{
A relação mãe-bebê prematuro na UTI neonatal: Um olhar Winnicottiano
}

\author{
The mother-premature baby relationship at the ICU: A Winnicott's look
}

La relación prematura madre-bebé en la UCI neonatal: Una mirada de winnicottian

Thatiana Rodrigues Alves Gomes ${ }^{1 *}$, Ana Flávia de Oliveira Santos²

\begin{abstract}
RESUMO
Objetivo: Identificar a vivência da mãe referente ao impacto do nascimento de um bebê prematuro, descrevendo ainda, como se desenvolve a relação mãe-bebê no contexto de internação, bem como o papel da maternagem nesse contexto e suas implicações a partir do referencial psicanalítico winnicottiano. Revisão Bibliográfica: Verificou-se, que a mãe pode apresentar dificuldade em se vincular ao seu bebê prematuro, devido a sua condição de permanecer, por tempo indeterminado, internado. A mãe, muitas vezes, experimenta emoções desagregadoras relativas ao luto do bebê imaginado e à ameaça de sua morte, que necessitam ser acolhidas, aliando aos cuidados técnicos e médicos, deve ser realizado ainda o incentivo ao contato materno que ofereça ao bebê um ambiente suficientemente bom para o seu desenvolvimento. A importância da relação mãe-bebê como fundante do desenvolvimento de um indivíduo, contribuição atribuída à psicanálise e particularmente a Winnicott, possui reflexo na implementação de práticas de assistência humanizadas. Considerações finais: Conclui-se sobre a importância da presença viva, ativa e empática da mãe, que possibilite uma condição de se adaptar às necessidades do seu bebê, facilitando que sua experiência de vir-a-ser de modo menos intrusivo.
\end{abstract}

Palavras-Chave: Prematuro, Psicanálise, Centros de saúde materno-infantil.

\section{ABSTRACT}

Objective: To identify the mother's experience regarding the impact of the birth of a premature baby, also describing how the mother-baby relationship develops in the hospitalization context, as well as the role of mothering in this context and its implications from the Winnicottian psychoanalytic framework. Bibliographic Review: It was found that the mother may have difficulty bonding with her premature baby, due to her condition to remain in hospital indefinitely. The mother often experiences disruptive emotions regarding the imagined baby's grief and the threat of her death, which need to be welcomed, combined with technical and medical care, and encouragement should be given to maternal contact that provides the baby with a sufficiently comfortable environment. Good for your development. The importance of the mother-baby relationship as the founder of an individual's development, a contribution attributed to psychoanalysis and particularly to Winnicott, is reflected in the implementation of humanized care practices. Final Considerations: It is concluded about the importance of the mother's living, active and empathic presence, which enables a condition to adapt to the needs of her baby, facilitating her experience of becoming less intrusive.

Key words: Premature, Psychoanalysis, Maternal-child health centers.

\footnotetext{
${ }^{1}$ Universidade Estadual Paulista Júlio de Mesquita Filho (UNESP) Faculdade de Ciências e Letras, Araraquara-SP.

2 Instituto de Estudos Psicanalíticos de Ribeirão Preto, IEP-RP, Ribeirão Preto-SP.

*E-mail: gomes.thatiana@gmail.com
} 


\section{RESUMEN}

Objetivo: identificar la experiencia de la madre con respecto al impacto del nacimiento de un bebé prematuro, también describiendo cómo se desarrolla la relación madre-bebé en el contexto de la hospitalización, así como el papel de la madre en este contexto y sus implicaciones desde el marco psicoanalítico winnicotiano. Revisión bibliográfica: se descubrió que la madre puede tener dificultades para vincularse con su bebé prematuro, debido a su condición de permanecer hospitalizada indefinidamente. La madre a menudo experimenta emociones en desacuerdo con respecto al dolor imaginado del bebé y la amenaza de su muerte, que deben ser bienvenidas, junto con la atención médica y técnica, y se debe alentar el contacto materno que le brinda al bebé un ambiente lo suficientemente cómodo. Bueno para tu desarrollo. La importancia de la relación madre-bebé como fundadora del desarrollo de un individuo, una contribución atribuida al psicoanálisis y particularmente a Winnicott, se refleja en la implementación de prácticas de atención humanizada. Consideraciones finales: Se concluye sobre la importancia de la presencia viva, activa y empática de la madre, que permite que una condición se adapte a las necesidades de su bebé, facilitando su experiencia de volverse menos intrusiva.

Palabras clave: Prematuro, Psicoanálisis, Centros de Salud Materno-Infantil.

\section{INTRODUÇÃO}

Segundo Baretta APV e Oliveira ZM (2010), a gravidez saudável ocorre quando organismo feminino é lentamente preparado e adaptado para a maturidade sexual, através do corpo, para acolher, nutrir e trazer à vida um novo ser, assim como da mente, para poder compreender sua nova imagem de mulher, ter a possibilidade de desenvolver capacidade de ter paciência, de se dedicar ao outro e se diferenciar, resolver problemas, tolerar a contrariedade e de amar, disponibilidades a que denominam maternagem.

Raphael L (1997) apud Braga AF e Morsch D, (2004) pontua o período gestacional como contendo o grande mistério de dois corpos em um só sem haver uma rejeição, um fenômeno que possibilita a experiência, logo na gestação, de continuidade como algo fundamental para a sobrevivência psíquica e senso de segurança de um bebê.

O uso do termo nascimento, representa o fim de uma gestação, como o momento em que o bebê sai do útero materno para fazer parte do mundo apartando da placenta (BARETTA APV e OLIVEIRA ZM, 2010). Sugere-se como período adequado para o acontecimento do nascimento aproximadamente 40 semanas, quando todos os órgãos se encontram amadurecidos (BARETTA APV e OLIVEIRA ZM, 2010). É, portanto, a partir da concepção e por meio de todo o período gestacional que o bebê pode reunir condições físicas iniciais que permitam sua sobrevivência fora do útero (respiração, controle cardíaco, entre outros), de maneira sadia, com o mínimo de trauma para a mãe, cujo nascimento não significa uma separação emocional, mas sim o surgimento das funções mãe e filho (RAMOS HAC e CUMAN RKN, 2009).

Segundo Bragheto ACM e Jacob AV (2011), o nascimento de um bebê, representa o registro biológico dos desejos conscientes e inconscientes dos pais em uma terceira vida. Além disso, segundo as autoras, o nascimento formula novas funções na mulher e homem para a sociedade, pois favorece um novo contexto relacional. Desta forma, o nascer não possui apenas conotação biológica, podendo-se falar de um nascimento emocional que acontece na relação com o outro que possa prover cuidado.

Com o nascimento de um bebê, faz-se importante uma série de cuidados que permitam que ele possa se desenvolver, propiciado pela função materna, desempenhada pela mãe ou por substituto (BRAGHETTO ACM e JACOB AV, 2011). As primeiras relações da vida de um bebê são fundamentais, sendo consideradas favorecedoras do desenvolvimento da personalidade. Winnicott, psicanalista inglês, foi um teórico, dentre outros, que descreveu essas relações iniciais. $O$ autor acredita que, apesar de maduro fisicamente, ao nascer, o bebê necessita desenvolver-se emocionalmente através do amparo materno. Para ele, a maternagem encontra-se intrinsecamente relacionada ao desenvolvimento da saúde mental de todos os seres humanos (WINNICOTT DW, 1963).

REAS/EJCH | Vol.12(2) | e2422 | DOI: https://doi.org/10.25248/reas.e2422.2020 Página 2 de 8 
Winnicott DW (1956) afirma que a mãe, inicialmente, deve desenvolver a preocupação materna primária, onde um estado especial é desenvolvido durante a gravidez e algumas semanas após o nascimento, no qual a mãe, em uma fase de dependência absoluta que o bebê apresenta em relação ao ambiente, devotadamente, deve ser capaz de compreendê-lo, adaptando-se as suas necessidades, através da capacidade de identificação, constituindo uma unidade que auxilia o desenvolvimento emocional e a maternagem, estabelecendo-se as bases de um ambiente externo suficientemente bom e acolhedor.

Assim, como apontam Santos NTG e Zorning S (2014), a mãe pode saber o que ele está sentindo através de suas próprias experiências, o que auxilia o bebê em seu processo de integração (organizar pulsões, instintos, capacidades perceptivas e motoras). Por isso, Winnicott DW (1945) considera que não há bebê sem a mãe nem a mãe sem o seu bebê; sendo que o desenvolvimento emocional só ocorre diante de um ambiente suficientemente bom, ou seja, aquele que possibilite o bebê alcançar cada etapa do desenvolvimento que envolva um cuidado externo (manipulação, embalo, aleitamento, nomeação, etc.) físico e também emocional, possibilitando a sustentação do bebê (WINICOTT, 1954).

Para Santos NTG e Zorning S (2014), o fracasso nessa relação faz com que o bebê vivencie a sensação de se tornar um corpo com partes soltas, podendo desenvolver um sentimento de perseguição aniquiladora, ambas acarretando o surgimento de patologias mentais por falhas primitivas no desenvolvimento geralmente reativas à invasão, que cessam o continuar a ser. Bragheto ACM e Jacob AV (2011) afirmam que o próprio nascimento, então, representa uma ruptura imaginária entre a mãe e o bebê, no entanto suportável, e que, diante do nascimento prematuro, o cenário que se forma, pode despertar não apenas o luto pelo bebê imaginário, mas também em relação ao real, com um bebê que corre risco de vida ou até mesmo uma morte anunciada.

Braga AF e Morsch ELFJ (2004), afirmam que para ser considerado como um bebê prematuro é preciso que este nasça antes de completas 37 semanas de gestação. As autoras afirmam que, atualmente, a tecnologia vem aumentando ainda mais as possibilidades na área neonatal, assim, pode-se proporcionar sobrevida a bebês prematuros com idades gestacionais ainda mais baixas ( 24 ou 25 semanas). Isto posto, o bebê prematuro não finaliza, seu desenvolvimento no ambiente intra-uterino, ocorrendo uma separação antecipada da mãe, o que exige que o bebê se torne capacitado e competente à vida extra-útero antes da hora, precisando ir para a unidade de cuidados intensivos a fim de continuar seu processo longe da mãe (BRAGA AF e MORSCH ELFJ, 2004).

Segundo a Organização Mundial de Saúde OMS, (2004) apud Lamy ZC, et al., (2005), todos os anos nascem pelo menos 20 milhões de recém-nascidos no mundo, a grande maioria destes faz parte dos partos prematuros e contribui para a elevação da taxa de mortalidade neonatal ainda existente. No entanto, devido às condições em que o bebê prematuro nasce, enfatiza-se há a necessidade de intervenção em UTI Neonatal, onde a função dos cuidados intensivos, neste contexto, para Braga AF e Morsch ELFJ (2004), diz respeito à manutenção e acompanhamento das funções do bebê, que antes eram realizadas pelo corpo materno e que, dada à prematuridade, são sobrepostas ao serem mantidas pelos recursos da tecnologia médica (berço aquecido, incubadora, máquinas que auxiliam na respiração, no controle de oxigenação, no monitoramento dos batimentos cardíacos).

Considerando este complexo âmbito de intervenção que envolve o nascimento prematuro e questiona-se sobre o impacto desta na relação inicial mãe-bebê, necessária ao desenvolvimento emocional primitivo. Por meio desta pesquisa, busca-se compreender como os estudos identificam a ocorrência dessa relação em se considerando a prematuridade do bebê, além de aprofundar a discussão a partir do referencial psicanalítico winnicottiano de formas de atendimento no contexto de UTI.

\section{REVISÃO BIBLIOGRÁFICA}

\section{Relação mãe-bebê da gestação ao nascimento}

Para Esteves CR, et al. (2011), no período gestação, uma série de elaborações é exigida da mulher, tais como: mudanças psicológicas, corporais e sociais, quando há ameaça do nascimento de um bebê prematuro 
pode-se impactar de forma significativa a experiência gestacional. Essa vivência pode acarretar sofrimento e sentimentos ambivalentes que podem incidir inclusive na relação com o bebê que já começa a ser estabelecida na gravidez.

A relação inicial da mãe-bebê e sua importância tem sido bastante estudada, Winnicott foi um teórico dentro da psicanálise que desenvolveu amplamente essa temática. Moreira JO (2007), baseando-se neste teórico, refere que, após o nascimento, o cuidado da mãe pode mitigar a experiência de nascimento que elevou a carga de intrusão vivenciada pelo bebê. Porém, segundo a autora, quando a gestação é interrompida por um nascimento prematuro, que gera um excesso e prolongamento de intrusões, e sem cuidado materno, pode conferir a qualidade de traumático à experiência (GOMES ALH, 2004).

\section{Relação mãe-bebê prematuro: Contribuições de DW Winnicott}

Para Braga N e Morsch D (2004), a prematuridade demanda um trabalho árduo do bebê despreparado, o que pode gerar uma experiência de ruptura e uma vivência de desamparo pela ausência de experiência de continuidade na falta da placenta e da figura materna. Este contexto de experiências traumáticas, para Moreira JO (2007), segundo a teoria de winnicott, pode ser registrado, como traços de memória de dor, que podem aparecer no futuro sob a forma de sintomas (distúrbios alimentares, pânico de se machucar, etc.).

Gomes ALH (2001) aponta que, a mãe, não podendo finalizar o terceiro trimestre da gravidez, pode psicologicamente não ter desenvolvido ainda condições de lidar com o nascimento, além de se deparar com um bebê ainda bastante fragilizado, diferente do imaginado. Assim, Neves PN, Ravelli APX e Lemos JRD (2010), afirmam que o nascimento de um bebê pré-termo pode gerar medo, insegurança, culpa e preocupações. Pergher DNQ, et al. (2014) enfatizam ainda vivências emocionais desfavoráveis como: frustrações, luto e possibilidade de morte do bebê, que devem ser elaboradas para não prejudicarem a capacidade da mãe de se vincular ao seu bebê, já que esta, muitas vezes, pode cair no vazio (ser colocada no lugar daquela incapaz de propiciar ao bebê os cuidados necessários à sobrevivência) (SZEJER, 1999 apud GOMES ALH, 2004).

Para Pergher DNQ, et al. (2014), as especificidades da prematuridade incidem no estabelecimento do vínculo mãe-bebê, bem como no desenvolvimento da maternagem. A internação, segundo Gomes ALH (2001), ainda que fundamental para garantir a sobrevivência do bebê, por outro lado, pode impactar no vínculo. O autor enfatiza relatos de mães que, no começo da internação do bebê, referem a fragilidade deste e mesmo o receio que sentem de tocá-lo. Para Braga N e Morsch D (2004), a perda da placenta é considerada a mais significativa, podendo ocasionar uma sensação de falta de continuidade, pois ela era responsável por oferecer as condições necessárias ao bebê intra-útero e pela produção hormonal que mantém mãe e bebê ligados, o que é feito agora por aparelhos.

Braga $N$ e Morsch $D$ (2004) afirmam que o bebê prematuro não teve o tempo necessário para se preparar para a separação do corpo materno, o que pode gerar o sentimento de solidão ao longo de vida. Pode-se entender, assim, que, sendo prematuro e necessitando de intervenção e internação, poderá também não usufruir apropriadamente de uma ligação com a mãe estabelecida por meio de uma relação. Assim, a relação inicial mãe-bebê fica prejudicada, incidindo sobre o vínculo e sobre o comportamento adaptativo da mãe, que vão contra os estudos que consideram o pensamento winnicottiano da importância do vínculo da mãe com o bebê para o desenvolvimento deste (MOREIRA JO, 2007; PERGHER DNQ, et al., 2014).

\section{Intervenção médica na Uti-neonatal: imposições e reflexos na relação mãe-bebê.}

Em virtude da necessidade de intervenção médica do bebê, diz-se que dificulta o estabelecimento da chamada "preocupação materna primária" (GOMES ALH, 2004, MOREIRA JO, 2007, PERGHER DNQ, et al., 2014). Esse conceito winnicottiano se refere a um estado de sensibilidade aumentada, no qual a mãe voltase inteiramente para seu bebê (WINNICOTT DW, 1956).

Seria como se o bebê fizesse parte da própria mãe e ela, através de uma identificação com seu bebê, pode saber o que ele está sentindo através de suas próprias experiências. Esse estado pode ser considerado como um adoecer do qual a mãe deve se recuperar progressivamente até que o desenvolvimento do filho 
passe a dispensá-la. Para viver esse momento, Winnicott DW (1945) afirma, então, que a mãe precisa ter um desenvolvimento emocional sadio e um ambiente protetor que a sustente, para que não seja intrusivo, nem ausente. O exercício adequado dessa função diz respeito à possibilidade de um ambiente ser "suficientemente bom", ou melhor dizendo, um ambiente na medida certa para atender às necessidades do bebê, no tempo e da maneira adequada que possibilite ao bebê ir se integrando.

Segundo Moreira JO (2007), em uma vertente winnicottiana, devido à interrupção da gestação na prematuridade, a mãe, também prematura, pode não estar pronta para assumir o estado particular de "preocupação materna primária". Isso quer dizer não ter alcançado um estado de sensibilidade e enamoramento pelo bebê que é de extrema importância para o desenvolvimento do mesmo (Winnicott DW, 1963).

Para Moreira JO (2007), a "[...] situação de fragilidade do bebê e o estado de angústia livre podem conduzir a mãe a uma 'fuga para a sanidade', ou seja, a um distanciamento desse bebê que ela não sabe se vai viver". Não conseguindo estabelecer a preocupação materna primária, essas mães podem sentir dificuldade em se identificar com o seu bebê e em se adaptar as suas necessidades (GOMES ALH, 2001), em um momento em que, dada a sua condição de prematuro, essa identificação se mostra primordial.

Segundo Winnicott DW (1963), nesse estado de dependência absoluta, a mãe, não conectada ao bebê, produz no mesmo um estado de não-integração, trazendo o sentimento de corpo com partes soltas, assim como, uma sensação de perseguição aniquiladora, ambas acarretando o surgimento de patologias mentais por falhas primitivas no desenvolvimento. Assim, repetição intensa dessa experiência de fracassos maternos, prejudicaria o desenvolvimento do bebê, cessando o seu "continuar a ser" pela ameaça de aniquilamento do próprio self.

No estudo de caso de Esteves CR, et al. (2011), em mães com possibilidade de parto prematuro (identificada no início da gestação), pôde-se observar dificuldades tais como: não desejar a gravidez (agravada pela ameaça do parto), nem a realização do acompanhamento pré-natal ou um retardamento no aparecimento de indicadores do estado de preocupação materna primária (algo que, em alguns casos, ocorreu apenas com o passar do tempo de gestação); além de preocupação da mãe com a sobrevivência do filho e com a sua própria no parto, aumento da sensibilidade materna de forma exacerbada, o que, para os autores winnicottianos, significaria uma rigidez ou inadaptabilidade da mãe (devido à ansiedade ou a estados depressivos), que pode gerar consequências graves ao desenvolvimento emocional do bebê.

Os autores destacaram alguns dados de que após a aceitação da prematuridade, as mães estudadas puderam desenvolver alguns fatores positivos que ocuparam o lugar das adversidades, como por exemplo: gradual construção simbólica do lugar do filho nos preparativos para a chegada do mesmo; sintonia das mães com os bebês e percepção em relação a ele.

Agman M, et al., (1999) apud Esteves CR, et al., (2011) afirmam a importância da, após o nascimento prematuro, "preocupação materna primária" não ser substituída pelo que denominam de "preocupação médico-primária", onde a mãe que, não podendo assumir a função materna, ocupa-se de uma função "médica", ficando ligada a aspectos técnicos da internação, como examinar minuciosamente o prontuário com o intuito de rivalizar com a equipe da UTI a respeito das informações médicas; permanecer apenas ao lado da incubadora ou berço, mas sem manifestar um olhar zeloso e cuidadoso.

A respeito das funções maternas, Winnicott DW (1963) acredita que o bebê necessita desenvolver-se física e emocionalmente através, como já dito, do amparo materno, por meio do que denominou handling, que são os cuidados físicos dispensados ao bebê (manipulação), e o holding, que lhe oferece uma sustentação emocional (associado ao ser segurado no colo). É a repetição desses comportamentos que instauram o encontro e a comunicação necessários para o desenvolvimento emocional do bebê. Assim as funções maternas de holding, handling e apresentação de objetos (que determina a relação objetal, na qual mãe apresenta o mundo gradualmente, respeitando o ritmo de desenvolvimento do bebê), também devem ser consideradas condições indispensáveis para que o bebê possa sentir-se um todo (integração), habitar um corpo (personalização satisfatória) e relacionar-se com o ambiente externo (WINNICOTT DW, 1945). Nesse 
aspecto, para Moreira JO (2007), se a mãe puder acolher o bebê prematuro em seus braços ou apresentar sua voz, poderia protegê-lo da angústia, no entanto, nem sempre isso acontece no contexto hospitalar.

Outra função da mãe que que necessita ser estimulada quando em situação de nascimento prematuro, é a função especular. Para Santos NIG e Zorning S (2014), pautando-se em Winnicott, a mãe, ao olhar para o bebê, deve enxergar, no novo ser, aquilo que está relacionado com sua própria imagem, por vezes também seu humor e sua rigidez quanto às defesas, formando-se, assim, uma unidade mãe-bebê, a partir da qual irá surgir o indivíduo integrado, personalizado, podendo apreciar o tempo, o espaço e outras propriedades da realidade. Quando, por outro lado, ao olhar para sua mãe, se o bebê não vê a si mesmo, a mãe estaria invadindo-o com sua reação, com seu gesto, numa posição de exterioridade que não permite a compreensão e restituição para o bebê de seus estados físicos e psicológicos bebê (MOREIRA JO, 2007; PERGHER DNQ, et al., 2014). Por ser uma situação em que a mãe costuma vivenciar experiências desagregadoras, pode-se supor que a mãe possua dificuldade em refletir o próprio bebê em seu olhar, ou mesmo acabe por devolver a ele sensações desestruturantes que possa vir a sentir, o que reafirma a necessidade de atenção voltada à mãe.

A situação de prematuridade, sem que os cuidadores voltem sua atenção para os bebês, ou seja, apenas com precisão técnica, e sem atenção humana "dialógica", portanto, para Moreira JO (2007), proporciona uma experiência de desamparo ao bebê, com o passar do tempo, pode se transformar em angústia de separação; tal separação entre mãe-bebê e "cuidado sem afeto" acarretam, à longo prazo, impactos nas crianças, que passam a apresentar medos, baixa autoestima, insegurança e dificuldades no relacionamento interpessoal e dentro deste aspecto segundo Bragheto ACM e Jacob AV (2011), um fator extremamente traumático para as mães de bebês prematuros que ficam internados é a situação em que muitas precisam voltar para casa sem eles, tendo assim que passar por vivências que contêm, além da impossibilidade de estabelecimento de vínculo, a situação de vivências de "espaços" vazios, tais como os braços e berços que não contêm bebê, o que gera um intenso sofrimento também nas mães.

É importante deixar claro, que por se considerar os estudos relativos à importância da relação mãe-bebê, aliado à Política Nacional de Humanização da assistência, visando, assim, práticas mais humanizadas no cuidado e na perspectiva de minimizar os efeitos negativos da internação neonatal no âmbito do nascimento prematuro, novos caminhos de participação da família passaram a ser estimulados, entre os quais se pode citar o Método Canguru (LAMY et al., 2005; MOREIRA JO, 2009). Segundo Padilha JF, Steidl EMS e Braz MM (2012), o método, propõe uma nova forma de cuidado que incentive a formação do vínculo entre mãe e bebê, além de uma preocupação com a subjetividade daqueles que se encontram envolvidos nesse processo, contemplando diferentes aspectos, tais como: cuidados técnicos com o bebê prematuro (manuseio, atenção às necessidades individuais); o acolhimento da família; o acompanhamento ambulatorial pós-alta; ênfase ao aleitamento materno e principalmente, ao contato pele a pele (LAMY ZC, et al., 2005).

Dessa maneira, Gomes ALH (2004) alerta quanto à necessidade de cuidado a uma sobreposição da técnica em relação ao contato mãe-bebê, sendo necessário uma "prevenção sistemática", ou seja, explicar às mães todas as competências do recém-nascido, estimulando sua aproximação através da percepção dos sinais de comunicação do bebê gradualmente. Para a autora, a relação mãe-bebê deve ser incentivada e priorizada. A equipe não pode se colocar como a "melhor mãe" para o bebê, pois isso pode bloquear o relacionamento mãe-bebê. Assim, segundo a autora, a função da equipe é a de harmonizar o acolhimento do bebê e também da mãe, ajudando-a e respeitando seu tempo quanto a significar e lidar com o momento de prematuridade extrema e recuperação/desenvolvimento do bebê; ou seja, a mãe, além do bebê, também deve ficar de alguma forma internada, necessitando de um ambiente suficientemente bom que acolha suas angústias e a ampare em suas vivências diante da prematuridade do seu bebê e necessidade de internação bebê (MOREIRA JO, 2007; PERGHER DNQ, et al., 2014).

\section{CONSIDERAÇÕES FINAIS}

O nascimento de um bebê prematuro instaura vivências desconhecidas em todos os envolvidos e demanda intervenções que possibilitem a sobrevivência do bebê. A necessidade de internação, levando a

REAS/EJCH | Vol.12(2) | e2422 | DOI: https://doi.org/10.25248/reas.e2422.2020 Página 6 de 8 
uma separação que pode ser prolongada em relação à mãe, pode prejudicar os contatos iniciais, dificultando o desenvolvimento do vínculo. Uma vez que a maternagem é fundamental, a experiência e os estudos desenvolvidos ao longo dos anos apontam a importância de, aliado à assistência médica ao bebê, incluir a presença e o contato materno. Desse modo, o arcabouço teórico desenvolvido por DW Winnicott, a partir do paradigma da relação mãe-bebê, auxilia na compreensão da dinâmica vivenciada no contexto da prematuridade, além de contribuir para o desenvolvimento de intervenções humanizadas, que objetivem o desenvolvimento emocional do bebê. Assim, é de extrema importância que a mãe, no período de gravidez de risco e pós-parto, seja acompanhada através de atividades de prevenção e intervenção, através da escuta atenta e sensível, visando à promoção da saúde mental que terá influência direta no desenvolvimento emocional do bebê.

\section{REFERÊNCIAS}

1. ABRAM J. A linguagem de Winnicott: dicionário das palavras e Expressões utilizadas por Donald W. Winnicott. Rio de Janeiro: Ed. Revinter, 2000; 305 p.

2. ANDRADE ISN, GUEDES ZCF. Sucção do recém-nascido prematuro: comparação do método Mãe Canguru com os cuidados tradicionais. Revista Brasileira de Saúde Materno Infantil, 2005, 5: 61-5.

3. BARRETTO APV, OLIVEIRA ZM. O ser mãe: expectativas de primigestas. Rev. Saúde.Com, 2010; 6(1): 9-23.

4. BRAGA AF, OKASAKI EdeLFJ. Prevenção da prematuridade: papel da enfermagem. Rev Enferm UNISA, $2004 ; 5$ : 52-6.

5. BRAGA N, MORSCH D. Cuidado da família: maternagem ampliada (pais, irmãos e avós). Rio de Janeiro: Editora FIOCRUZ, 2004; $564 \mathrm{p}$.

6. BRAGHETO ACM, JACOB AV. Suporte psicológico às mães de prematuras em uma UTI Neonatal: relato de experiência. Florianópolis: Sal. E Transf. Soc, 2011; 1(3): 174-178.

7. ESTEVES CR, ANTON MC, PICCININI CA. Indicadores da preocupação materna primária na gestação de mães que tiveram parto pré-termo. Psic. Clin., 2011 23(2):75-99

8. FERNANDES PdeP. A função materna no contexto de prematuridade: uma revisão de literatura psicanalítica, RS. Dissertação (mestrado em Psicologia) - Instituto de Psicologia. Universidade Federal do Rio Grande do Sul, Porto Alegre, 2013; $30 \mathrm{p}$.

9. FLECK A. O Bebê imaginário e o bebê real no contexto de prematuridade, RS. Dissertação (mestrado em Psicologia) - Instituto de Psicologia. Universidade Federal do Rio Grande do Sul, Porto Alegre, 2011; 16 p.

10. FRIZZO GB, PICCININI CA. Interação mãe-bebê em contexto de depressão materna: aspectos teóricos e empíricos. Maringá: Psicologia em Estudo, 2005, 10(1): 47-55

11. GOLDENBERG M. A arte de pesquisar: como fazer pesquisa qualitativa em Ciências Sociais. $8^{\underline{a}}$ ed., Rio de Janeiro: Record, 2004; $107 \mathrm{p}$.

12. GIL AC. Métodos e técnicas de pesquisa social. 5.ed. São Paulo: Atlas, 1999; 248 p.

13. GOMES ALH. As especificidades do vínculo da mãe com o bebê pré-termo na situação de internação. Estilos clin., 2001 6(10): 89-100

14. GOMES ALH. A relação mãe-bebê na situação de prematuridade extrema: possibilidades de intervenção da equipe multiprofissional. Psicol. hosp., 20042 (2)

15. LAMY ZC, GOMES MAdeSM, GIANINI NOM, HENNIG MdeAS. Atenção humanizada ao recém-nascido de baixo peso - Método Canguru: a proposta brasileira. Ciênc. saúde coletiva, 2005 10(3): 659-668

16. LINHARES MBM, CARVALHO AEV, BORDIN MBM, CHIMELLO JT, MARTINEZ FE, JORGE SM. Prematuridade e muito baixo peso como fatores de risco ao desenvolvimento da criança. Ribeirão Preto: Paidéia, 2000, 10(18): 6069

17. MOREIRA JdeO; ROMAGNOLI RC, DIAS DAS, MOREIRA CB. Programa mãe-canguru e a relação mãe-bebê: pesquisa qualitativa na rede pública de Betim. Maringá: Psicologia em Estudo, Maringá, 2009 14(3): 475-483

18. MOREIRA JdeO. A ruptura do continuar a ser: o trauma do nascimento prematuro. Barbacena: Mental, 2007, 5(8): 91-106

19. NEVES PN, RAVELLI APX, LEMOS JRD. Atenção humanizada ao recém-nascido de baixo-peso (método Mãe Canguru): percepções de puérperas. Porto Alegre: Rev. Gaúcha Enferm, 2010 31(1): 48-54

20. PERGHER DNQ, et al. Nascimento e internação do bebê prematuro na vivência da mãe. São Paulo: Estilos clin., 2014 19(1): 40-56

21. RABELO A. A função simbólica da UTI neonatal. In R. O. Aragão (Org.), O bebê o corpo e a linguagem. São Paulo: Casa do Psicólogo, 2004 
22. RAMOS HÂdeC, CUMAN RKN. Fatores de risco para prematuridade: pesquisa documental. Esc Anna Nery Rev Enferm, 200913 (2): 297-304

23. RIOS IJdeA. Mãe e Bebê Prematuro Extremo: Possibilidade de Vínculo em Situação Adversa, São Paulo. Dissertação (mestrado em psicologia) Pontifica universidade Católica de São Paulo, São Paulo, 2007

24. SANTOS NdeTG, ZORNIND SAJ. Os primeiro tempos da maternidade: indiferenciação ou intersubjetividadena relação primitiva com o bebê. São Paulo: Estilos clin., 2014 19(1): 78-90

25. SCOCHI CGS et al. Incentivando o vínculo mãe-filho em situação de prematuridade: as intervenções de enfermagem no Hospital das Clínicas de Ribeirão Preto. Ribeirão Preto: Rev. Latino-Am. Enfermagem, 2003 11(4): 539-543.

26. SILVA FFda, PRADO SRLdeA. Método Mãe-Canguru: um novo paradigma na assistência ao recém-nascido e sua família. Rev Enferm UNISA, 2003 4: 51-5

27. WINNICOTT DW. Desenvolvimento emocional primitivo. In D. W. Winnicott, Da pediatria a psicanálise. Rio de Janeiro: Imago, 1945 p. 269-285.

28. Memórias do nascimento, trauma do nascimento e ansiedade. In: Da pediatria à psicanálise. Rio de Janeiro: Imago, 1949

29. A preocupação materna primária. Em D. W. Winnicott, Da Pediatria à psicanálise (D. Bogomoletz, Trad.) Rio de Janeiro: Imago, 1956 p. 399-405

30. Da dependência à independência no desenvolvimento do indivíduo. In D. W. Winnicott. O ambiente e os processos de maturação: Estudos sobre a teoria do desenvolvimento emocional (I. C. S. Ortiz, Trad.). Porto Alegre, RS: Artes Médicas, 1963

31. A experiência mãe-bebê de mutualidade. Em D. W. Winnicott, Explorações psicanalíticas (J. Abreu, Trad.) Porto Alegre: Artes Médicas, 1969 p.195-202

32. O brincar e a realidade. Rio de Janeiro, Imago, 1971

33. Família e Maturidade Emocional. In: A Família e o desenvolvimento individual. $2^{a}$ ed. São Paulo: Martins Fontes, 1997

34. Os bebês e suas mães. $3^{\underline{a}}$ Ed. São Paulo: Martins Fontes, 2006 